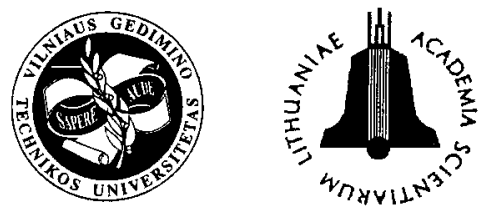

JOURNAL OF CIVIL ENGINEERING AND MANAGEMENT

http:/www.vtu.lt/english/edition

2002, Vol VIII, No 2, 138-142

\title{
DESIGN SOLUTIONS FOR LITHUANIAN GRAVEL ROAD PAVEMENTS
}

\author{
Donatas Čygas ${ }^{1}$, Daiva Žilioniené ${ }^{2}$ \\ Dept of Roads, Vilnius Gediminas Technical University, Sauletekio al. 11, LT-2040 Vilnius, Lithuania. \\ ${ }^{1}$ E-mail:dcyg@ap.vtu.lt ${ }^{2}$ E-mail: daizil@ap.vtu.lt
}

Received 04 Febr 2001; accepted 21 Febr 2002

\begin{abstract}
This article deals with the design problems of gravel road pavements. Mathematical models related to geological and hydrological conditions of a location, thickness of gravel pavement and characteristics of the gravel contained in this pavement are proposed to be used for pavements. For the selection of gravel pavements for reconstruction we recommend the models developed by the method of experimental planning to calculate the equivalent deformation modulus of the gravel pavements change depending on the deformation modulus of the subgrade, thickness of the gravel pavement and the materials used for its layers. Practical applications of these models will eliminate the mistakes that are still found in road pavement design.
\end{abstract}

Keywords: gravel pavement, equivalent deformation modulus, deformation modulus, subgrade.

\section{Introduction}

The present Lithuanian road network is relatively well developed. It is made up of more than $21000 \mathrm{~km}$ of roads. There is $1724 \mathrm{~km}(8,1 \%)$ of main roads, $4864 \mathrm{~km}(22,8 \%)$ of national roads and $14724 \mathrm{~km}$ $(69,1 \%)$ of regional roads. $2930 \mathrm{~km}(13,8 \%)$ of roads are concrete and asphalt concrete paved surfaces and $9128 \mathrm{~km}(42,8 \%)$ is asphalt paved. Asphalt concrete pavement types $(98,7 \% ; 6502 \mathrm{~km})$ prevail on the main and national roads, and gravel pavements $(62,1 \%$; $9149 \mathrm{~km}$ ) dominate on regional roads. However, a majority of Lithuanian gravel pavements on the regional roads are still to be improved.

The traffic, its composition and loads, influence the main requirements for road elements, pavement types and technologies. At present, there are 1,2 million vehicles of various types in Lithuania. Cars make up almost $80 \%$ of the total number of vehicles: trucks and buses make up approximately $8 \%$, and the remaining include other vehicles (motorcycles, minibuses, motor homes, articulated vehicles, car trailers, semi-trailers and trailers) [1]. The number of vehicles has increased by 1,5 times since 1990. Due to the traffic volume increase, requirements on the technical and operating characteristics of roads have risen. The number of heavy vehicles with constantly enlarging axle loads has been also increasing in traffic flows. The pavement deterioration has been speeded up by the fact that lower standard axle loads (8-10 t/axle) were applied to the earlier designed pavements, which do not conform to the current loads of heavy vehicles (11,5 t/axle). To approximate Lithuanian roads to Euro- pean standards and to reduce economical losses due to road conditions, many technical condition problems have been posed for improvements [2]. Due to an insufficient number of asphalt paved roads, our country incur losses up to $80 \mathrm{LT}$ mill per year and approximately $30 \mathrm{LT}$ mill per year - due to delayed repair of asphalt paved roads [3]. Losses inflicted due to insufficient road maintenance funding, impact on environment and other aspects were not taken into consideration in the past.

This research aims to identify gravel road renovation solutions taking into consideration climatic factors, soils, materials, and road pavements.

\section{The need of information for gravel road pavement design, repair and improvement}

When the technical and operating condition of roads weakens, the cost price of freight carriage increases. Vehicle traffic on gravel roads is less effective, and the vehicle operating costs increase on gravel roads because the calculated driving speed on these roads is $20 \%$ less than on asphalt paved roads. Compared with freight carriage on asphalt paved roads, the cost price of freight carriage on gravel roads increases by $1,35-1,9$ times. This cost price can be reduced if roads are properly maintained and repaired on time or if improved pavements are set especially on those roads with high traffic volumes ( $>251$ vehicles $/ 24$ hours) [4]. Therefore taking into consideration traffic volume and the composition of traffic flow this paper is aimed at solving gravel road repair and improvement problems. 
In $2000,270 \mathrm{~km}$ of gravel roads were repaired, ie $2,8 \%$ of their total length, and according to the 1998 2000 Paving of Gravel Roads Programme (hereinafter Programme), $9,9 \%$ of gravel roads were asphalt paved in Lithuania. The results of such gravel road repair and upgrading works are insufficient because according to the rates of this Programme in the country, the paving of gravel roads would take more than 30 years. However, it is not necessary to pave all gravel roads. Almost $3000 \mathrm{~km}$ of gravel roads will be asphalt paved immediately, one kilometre of which inflicts the loss of approximately $27000 \mathrm{LT}$ per year on average from the Lithuanian economy budget.

Gravel pavement will carry not only traffic loads but will also be resistant to shear deformation [5] and wear, ie they have to be of sufficient strength and durable. The strength of gravel pavement expressed by deformation modulus ( $\mathrm{E}, \mathrm{MPa}$ ) will carry traffic loads. Minimal deformation modulus (65 $\mathrm{MPa}$ ) on gravel pavements is required where annual average daily traffic is less than 50 vehicles/ 24 hours. When traffic volume is from 51 to 150 vehicles/24 hours, the deformation modulus will be not less than $80 \mathrm{MPa}$, and when traffic volume changes from 151 to 250 vehicles/24 hours -
$100 \mathrm{MPa}$. If traffic volume on gravel roads is higher than 251 vehicles/ 24 hours, the deformation modulus will be not less than $120 \mathrm{MPa}$.

When designing roads, the strength of the subgrade will be sufficient, ie deformation modulus $\mathrm{E}$ on the formation level will be not less than $45 \mathrm{MPa}$. This requirement is imposed on pavements, irrespective of traffic loads and the characteristics of the sugrade soil. If such strength cannot be achieved, its deficit will compensate by increasing thickness of the frost blanket course or using more resistant materials [6], ie their deformation modulus must be higher.

The deformation modulus of reconstructed roads on the formation level is heterogeneous and the following characteristics of soil influence it: type, relative moisture content, etc $[7,8]$. When designing pavements of reconstructed gravel roads, the characteristics of the existing subgrade soils will also be taken into consideration.

Therefore, much and varied information is required to solve problems related to gravel pavement design, repair and upgrading, according to the Regulation of Motor Roads (STR 2.06.03:2001). This information should be stored in a computer database, where infor-

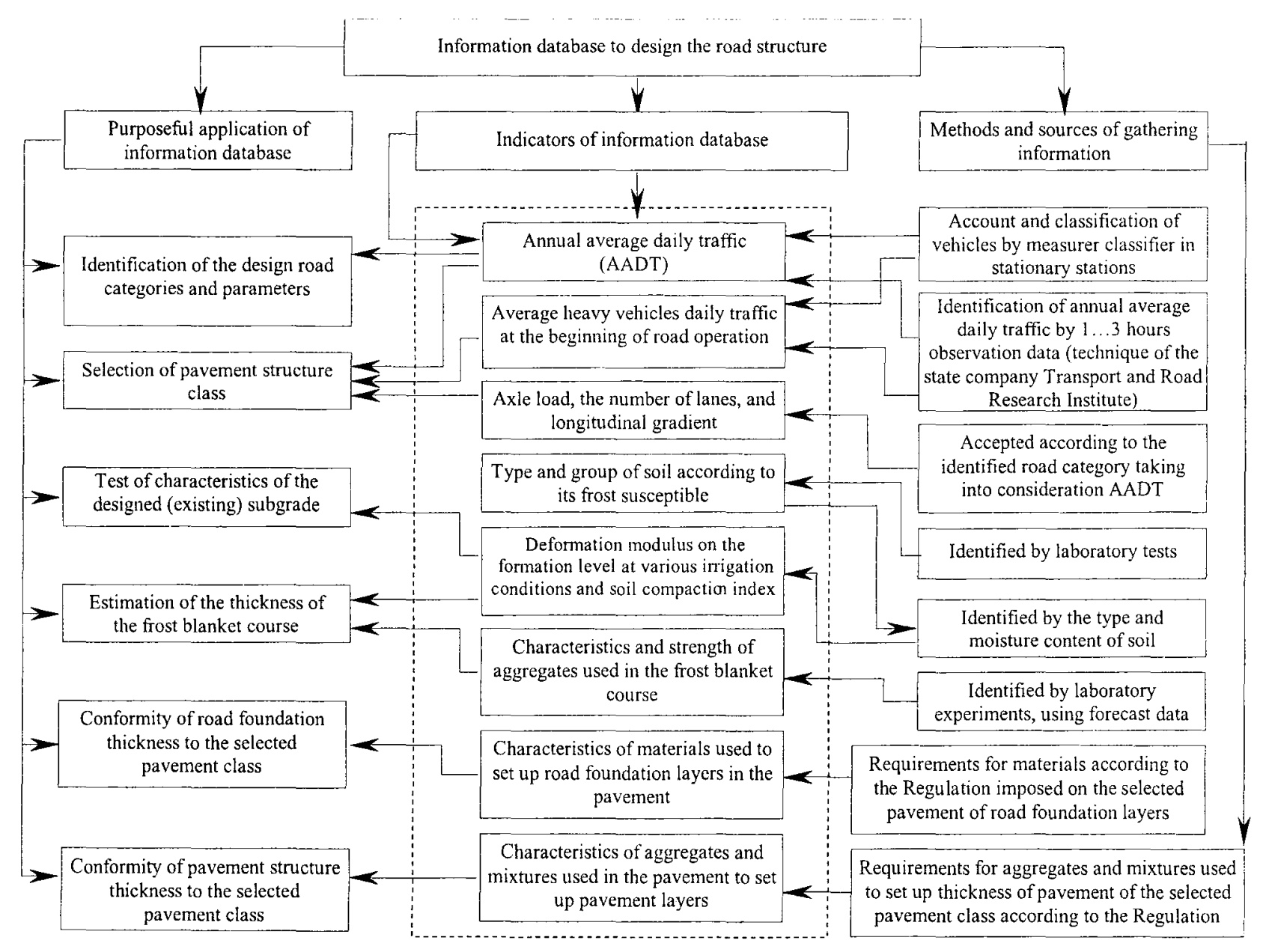

Scheme of the information database for designing road pavement according to the Regulation of Motor Roads (STR 2.06.03:2001) 
mation on the location, climate, traffic, geological, hydrological and other conditions is presented (Fig). In this case, when solutions of designing tasks were formed, a whole set of factors influencing the conditions of gravel road could be taken into account [9].

\section{The condition of gravel roads and their reconstruc- tion}

In 2000 , the experiments carried out by the Road Department of Vilnius Gediminas Technical University showed that gravel road classification according to traffic volume and the required deformation modulus of pavement varies in different regions (Table 1). Therefore, the scope of gravel road repair and upgrading work cannot be the same in different regions and regional road enterprises. When planning gravel road reconstruction work, we recommend taking the results of this research work into consideration.

Table 1. Distribution of gravel roads (in percent) by the required deformation modulus

\begin{tabular}{|c|c|c|c|c|c|c|}
\hline \multirow{5}{*}{$\begin{array}{l}\text { Name of } \\
\text { region }\end{array}$} & \multicolumn{6}{|c|}{$\begin{array}{l}\text { Required deformation modulus for gravel } \\
\text { road pavement, } \mathrm{MPa}^{*}\end{array}$} \\
\hline & \multicolumn{3}{|c|}{100} & \multicolumn{3}{|c|}{120} \\
\hline & \multicolumn{6}{|c|}{ Distribution of gravel roads, $\%$} \\
\hline & \multicolumn{2}{|c|}{$\begin{array}{l}\text { in separate } \\
\text { road } \\
\text { enterprises }\end{array}$} & \multirow{2}{*}{$\begin{array}{l}\text { on } \\
\text { average } \\
\text { in a } \\
\text { region }\end{array}$} & \multicolumn{2}{|c|}{$\begin{array}{l}\text { in separate } \\
\text { road } \\
\text { enterprises }\end{array}$} & \multirow{2}{*}{$\begin{array}{c}\text { on } \\
\text { average } \\
\text { in a } \\
\text { region }\end{array}$} \\
\hline & $\min$ & $\max$ & & $\min$ & $\max$ & \\
\hline Utena & 17,1 & 37,8 & 24,2 & 2,5 & 20,2 & 10,8 \\
\hline Telšiai & 39,8 & 58,9 & 49,2 & 15,6 & 17,7 & 16,7 \\
\hline Kaunas & 19,3 & 46,5 & 32,0 & 0 & 30,8 & 6,7 \\
\hline Marijampole & 22,4 & 43,3 & 31,9 & 0 & 4,8 & 1,6 \\
\hline Šiauliai & 0 & 45,9 & 26,5 & 5,4 & 32,1 & 20,8 \\
\hline Tauragé & 210 & 33,8 & 28,5 & 15,6 & 36,9 & 28,0 \\
\hline Panevèžys & 10,5 & 27,8 & 22,6 & 5,5 & 31,8 & 18,1 \\
\hline Klaipeda & 7,2 & 38,9 & 22,1 & 0 & 13,6 & 9,5 \\
\hline Alytus & 5,5 & 41,2 & 26,7 & 5,0 & 27,8 & 10,4 \\
\hline Vilnius & 0 & 30,0 & 14,8 & 0 & 11,8 & 4,9 \\
\hline
\end{tabular}

Note: * - results of research work.
When implementing the Programme in Lithuania, four pavement types were set up (two types per settlement and on road sections between settlements). The usage of these pavements was not related to the local geological and hydrological conditions, the thickness of the gravel pavement and characteristics of the gravel material in gravel pavement. When selecting the type of gravel pavement, we recommend using models simulated by the method of the experiment planning and the presented conclusions.

Levels and variation intervals of factors influencing the strength [10] of gravel pavements, which were set up on the subgrade of various frost susceptible soils identified during our experiments are presented in Table 2.

Variation limits of the subgrade strength were identified in our experiments by taking into consideration frost susceptibility and the moisture content of soils. It was found that gravel deformation modulus varies from 150 to $200 \mathrm{MPa}$ depending on the percentage of grading and fines of gravel material $(<0,063 \mathrm{~mm})$. Hence the main accepted level in experiments is $175 \mathrm{MPa}$ at the variation interval of $25 \mathrm{MPa}$.

The main level of gravel pavement thickness for the subgrade set up of frost susceptible, medium frost susceptible, low frost susceptible or frost insusceptible soils varies and is equal to 50,45 and $40 \mathrm{~cm}$, respectively.

When applying the method of experimental planning [11], we estimated that fluctuations were of equivalent gravel pavement deformation modulus $\mathrm{E}_{\text {ekv }}$ described by binomial are wide ((1), (2) and (3) formulae)) when the thickness of gravel pavement and deformation modulus of the material used for these layers vary.

1. Gravel pavement is set up on the subgrade of frost susceptible soils (clay and silt):

$E_{e k v}=96,6+13,1 E_{g r}+6,9 E_{\check{z} v}+15,1 h_{z v}+2,9 E_{g r} E_{z v}+2,8 E_{z v} h_{z}$

II. Gravel pavement is set up on the subgrade of medium frost susceptible soils (clay sand, clay gravel, silty sand and silty gravel):

$$
E_{e k \nu}=102,1+3,4 E_{g r}+9,4 E_{z \nu}+12,6 h_{z \nu}+2,9 E_{z \nu} h_{z v}
$$

III. Gravel pavement is set up on the subgrade of low frost susceptible or frost insusceptible soils (sand and gravel):

Table 2. Indicators of factors influencing the gravel pavement strength depending on the frost susceptibility of subgrade soils

\begin{tabular}{|l|c|c|c|c|c|c|}
\hline \multirow{2}{*}{ Factors } & \multicolumn{2}{|c|}{ Deformation modulus, MPa } & \multicolumn{3}{c|}{ Thickness of gravel pavement (cm) when subgrade } \\
soils
\end{tabular}

Note: Deformation modulus of low frost susceptible or frost insusceptible soils vary slightly when soil moisture changes. 
$E_{e k v}=109,8+9,2 E_{\check{z} v}+8,8 h_{\check{z} v}+2,2 E_{\check{z} \nu} h_{\check{z} v}$

In (1), (2) and (3) formulae: $E_{e k v}$ - equivalent deformation modulus of a gravel pavement, $\mathrm{MPa} ; E_{g r}-$ modified value of soil deformation modulus (upper level " +1 " and bottom level "-1"), $\mathrm{MPa} ; E_{z v}$ - modified value of deformation modulus of gravel material (upper level "+1" deformation modulus $200 \mathrm{MPa}$ and bottom level " -1 " deformation modulus $150 \mathrm{MPa}) ; h_{z v}-$ modified value of the thickness of the gravel pavement ("+1" upper level of the thickness of the gravel pavement and " 1 " - bottom level of the thickness of the gravel pavement), $\mathrm{cm}$.

When a gravel pavement is set up on the subgrade of frost susceptible soils (formula (1)), both the thickness of the gravel pavement (coefficient 15,1) and the deformation modulus of the subgrade (coefficient 13,1) have the greatest impact on the strength of a gravel pavement. Deformation modulus of the subgrade decreases by $47 \%$ (from 45 to $24 \mathrm{MPa}$ ) when relative moisture content of the soil increases from 0,6 to 0,8 .

Under the most unfavourable conditions (saturated subgrade soil, minimum (bottom level) thickness of a gravel pavement and gravel deformation modulus), equivalent deformation modulus of a gravel pavement is only $67,2 \mathrm{MPa}$. Under the most favourable conditions (ie when the relative moisture content of the subgrade soil does not exceed 0,6 , the maximums (upper level) thickness of a gravel pavement and gravel deformation modulus) deformation modulus of gravel pavement increase up to $137,4 \mathrm{MPa}$, ie more than twice.

Therefore the sufficient deformation modulus of a gravel pavement $(120 \mathrm{MPa})$ will be on those road sections where the surface water culverts are properly fixed and the required distance (not less than $2 \mathrm{~m}$ ) from the ground water horizon up to the bottom of the pavement is maintained. In this case, the pavement thickness will be $50 \mathrm{~cm}$, and gravel deformation modulus not less than $200 \mathrm{MPa}$.

When a gravel pavement is set up on the subgrade of medium frost susceptible soils (formula (2)), the gravel pavement thickness variation has the greatest impact on the equivalent deformation modulus of the gravel pavement. Equivalent deformation modulus of a gravel pavement increases by $12,6 \mathrm{MPa}$ at the thickness part of the gravel pavement of $60 \mathrm{~cm}$ (upper level), and decreases by the same rate at the thickest of the gravel pavement of $30 \mathrm{~cm}$ (bottom level). In this case, the strength of the gravel pavement is highly influenced by gravel deformation modulus (coefficient 9,4) and the multiplication of both factors mentioned above (coefficient 2,9), whereas the influence from the increase of the moisture content in the subgrade is four times less (coefficient 3,4) than in the subgrade of frost susceptible soils (coefficient 13,1). The lowest gravel pavement deformation modulus, estimated according to formula (2) is $73,8 \mathrm{MPa}$ and the highest is $130,4 \mathrm{MPa}$.

When gravel pavements are set up on low frost susceptible or frost insusceptible soils (formula (3)), gravel deformation modulus and the thickness of the gravel pavement have almost the same influence on the strength of a gravel pavement. The required gravel pavement deformation modulus of $120 \mathrm{MPa}$ can be reached when setting up $50 \mathrm{~cm}$ (upper level) of the thickness of a gravel pavement, the deformation modulus of which would be $180 \mathrm{MPa}$. In this case the strength of soil is not taken into account because the strength of low frost susceptible and frost insusceptible soils does not change when the moisture content varies. In this case, the equivalent deformation modulus of gravel pavement can change from 89,6 to $130,0 \mathrm{MPa}$ due to the thickness of the gravel pavement and the gravel deformation modulus variation.

Following formulae $(1,2,3)$ presented above, the strength of pavement is mostly influenced by the strength of the frost susceptible soil, which decreases when relative moisture content of soils increases.

Characteristics of soils on the formation level deteriorate due to a number of reasons on operated roads. The formation level is contaminated with fine gravel wearing particles, which settle on the surface with water. When these particles accumulate, they increase the amount of clay and silt in soil. The soil reciprocal viscosity indicator increases, and its deformation modulus decreasing at the same time. The research showed that the deformation modulus of clay and silt moraine soils decreased when their reciprocal viscosity indicator increased:

$$
E_{g r}=50,9+\frac{3,2}{e}-58,8 I_{l},
$$

where $E_{g r}$ is deformation modulus of the soil, MPa; $e$ is soil void content coefficient; $I$, is reciprocal viscosity indicator estimated according to the following formula:

$$
I_{l}=\frac{\left(W-W_{p}\right)}{I_{p}},
$$

where $W$ is natural moisture content of the soil, $\% ; W_{p}$ is plasticity moisture content of the soil, $\% ; I_{p}$ is soil plasticity indicator.

Geological distribution of soils in the Republic of Lithuania has been investigated comprehensively. However, soils found in the subgrade do not comply with this distribution because they are remixed during the technological process of road construction (soils are brought from quarries, moved from trenches, etc). Having investigated gravel pavements under reconstruction, we could state that these pavements were not always cost-effective because the local soil conditions were not completely taken into consideration. This it can be illustrated by an example presented in Table 3 .

Having investigated soils of road Širvintos Šešuoliai and Varéna - Marcinkonys - Druskininkai, we found that their characteristics are completely different and pavements are the same. Research results show that the strength of the subgrade varies on these roads. 
Table 3. Characteristics of subgrade soils

\begin{tabular}{|l|c|c|c|c|c|}
\hline \multirow{2}{*}{ Road } & \multicolumn{2}{|c|}{ Pavement structure } & \multicolumn{3}{|c|}{ Characteristics of subgrade soil } \\
\cline { 3 - 6 } & & $\begin{array}{c}\text { deformation } \\
\text { modulus, MPa }\end{array}$ & $\begin{array}{c}\text { moisture } \\
\text { content, \% }\end{array}$ & $\begin{array}{c}\text { coefficient of } \\
\text { void content }\end{array}$ & $\begin{array}{c}\text { reciprocal } \\
\text { viscosity } \\
\text { indicator }\end{array}$ \\
\hline Širvintos-Šešuoliai & $\begin{array}{l}6 \mathrm{~cm} \text { thick one-layer asphalt } \\
\text { concrete pavement } \\
10 \mathrm{~cm} \text { thick subgrade of sand- } \\
\text { gravel mixture by adding 40\% } \\
\text { of dolomite crushed stone }\end{array}$ & $78-46$ & $12,5-17,7$ & $0,39-0,50$ & $0,02-(-0,7)$ \\
\cline { 1 - 5 } $\begin{array}{l}\text { Varena-Marcinkonys- } \\
\text { Druskininkai }\end{array}$ & $76-122$ & $4,6-8,7$ & $0,53-0,67$ & - \\
\hline
\end{tabular}

However, various pavement types will be used on these roads, ie a simpler pavement could be used on the road Varèna - Marcinkonys - Druskininkai.

When solving problems of the reconstruction of gravel pavements, more data about the existing pavements are required. The results of our research work enabled us to use the data when constructing pavements, and to improve the efficiency of ground gravel road by using the World Bank economic model HDM-4 [12].

\section{Conclusions}

1. The Lithuanian road network is relatively well developed; however, due to the increased traffic and loads, roads and their pavements do not comply with the requirements established by the traffic and European standards. Due to insufficient amount of asphalt paved roads, our country incurs losses up to $80 \mathrm{LT}$ mill per year. The condition of Lithuanian gravel roads does not ensure the efficient operation of vehicles, especially on those roads where the annual average daily traffic is more than 251 vehicles/ 24 hours.

2. Reconstructed gravel roads have to be strength and durable. When gravel roads are asphalt paved, their equivalent deformation modulus $\left(\mathrm{E}_{\mathrm{ekv}}\right.$ ) on the gravel pavement surface will be not less than $120 \mathrm{MPa}$, irrespective of the traffic and the characteristics of the subgrade soil.

3. The strength of gravel pavements depends on the strength of the various subgrade soils and frost insusceptible soils that depend on the subgrade irrigation conditions and rate. Thus, specifications of various gravel pavements, which are set up on different subgrade soils, will be taken into account when gravel roads are reconstructed.

4. Since it is difficult and economically inefficient to change subgrade soils when reconstructing gravel roads we recommended applying simulated models according to the method of experiment planning. That is in situations when the actual strength of the subgrade soil, thickness of gravel pavement and strength of the gravel material are taken into consideration and when reconstructing gravel roads, as well as estimating the equivalent deformation modulus of a gravel pavement.

5. The formation level of the subgrade on operated roads is contaminated with fine wearing particles as well as clay and silt particles, which are carried by capillary water from the sublayers of the subgrade. Therefore in the course of time characteristics of the subgrade soil change: reciprocal viscosity indicator increases and deformation modulus decreases.

\section{References}

1. Lithuanian Yearbook of Statistics (Lietuvos statistikos metraštis). Vilnius: Methodical and Publishing Centre, 1999. 592 p. (in Lithuanian).

2. Puodziukas V., Kamaitis Z. Asphalt Concrete Pavement Strengthening and Modelling of its Effect on Road Evenness. Civil Engineering (Statyba), Vol V, No 6. Vilnius: Technika, 1999, p. 386-393 (in Lithuanian).

3. Domantas A., Puodziukas V. The Planned Budget Will Cover Only Part of Necessary Funds. Lithuanian Roads (Lietuvos keliai), 1999/1. 1999, p. 14-19 (in Lithuanian).

4. Skrinskas S. Research on the Condition of Lithuanian Gravel Roads and Feasibility of their Renovation: Summary of Doctoral dissertation. Vilnius Gediminas Technical University. Vilnius: Technika, 1998. 32 p.

5. Miller G. A., The S. Y., Li D., and Zaman M. M. Cyclic Shear Strength of Soft Railroad Subgrade. Journal of Geotechnical and Geoenvironmental Engineering, Vol 126, No 2, 2000, p. 139-147.

6. Masih R. Formula to Get Desired Soil Density. Journal of Geotechnical and Geoenvironmental Engineering, Vol 126, No 12,2000 , p. 1145-1150.

7. Khire M. V., Benson C. H., and Bosscher P. J. Capillary Barriers: Design Variables and Water Balance. Journal of Geotechnical and Geoenvironmental Engineering, Vol 126, No 8, 2000, p. 695-708.

8. Alikonis A. Influence of Clayey Soil Structure on its Modulus of Stiffness. Civil Engineering (Statyba), Vol IV, No 4. Vilnius: Technika, 1998, p. 283-291 (in Russian).

9. Croney D., Croney P. Design and Performance of Road Pavement. NY: McGraw-Hill, 1997. 509 p.

10. Puppala A. J., Mohammad L. N. and Allen A. Permanent Deformation Characterization of Subgrade Soils from RLT test. Journal of Materials in Civil Engineering, Vol 11, No 4, 1999, p. 274-282.

11. Johnson N., Leone F. Statistics and Planning of the Experiment in Technology and Research. Methods of Planning Experiments. Moscow: Mir, 1981. 510 p. (in Russian).

12. Highway Development and Management (HDM -4). Overview of HDM-4. T. 1 Vol 1, World Road Association, 2000. 53 p. 